\title{
Special Issue: ICT Trends for Future Smart World
}

\author{
Milica Pejanović-Djurišicí ${ }^{1} \cdot$ Liljana Gavrilovska $^{2}$ • \\ Octavian Fratu ${ }^{3}$
}

Published online: 29 November 2016

(C) Springer Science+Business Media New York 2016

Predicting the trends in info-communication technologies and their applications is not an easy task. It is even more difficult following dramatic changes and constantly rising opportunities for innovation. Nowadays, info-communication technologies are developed as centered on integration platforms with wide ranges of implemented services and applications. Such applications and services are offered to the society for fostering the evolutions of the modern living and working in smart environments. They represent a topic that calls for exchange of various knowhow from developers, researchers, stakeholders, business/regulatory/civil sector etc., so that the research and development challenges to create a smart world would be efficiently addressed.

The primary goal of future info-communication integration platforms is in line with the paradigm of being connected anytime, anyplace, with anything and anyone. In such circumstances the communication should be based on interoperable protocols, operating in heterogeneous scenarios. In this context, Internet of Things (IoT) can be considered as a generic platform where all objects play an active role in creating smart environments. It is a multidisciplinary eco system that encompasses a wide range of various scenarios and technologies, application domains, business strategies, industry stakeholders. Thus, there is no doubt that the evolution of ICT towards creating integration platforms implies the

Milica Pejanović-Djurišić

milica@t-com.me

Liljana Gavrilovska

liljana@feit.ukim.edu.mk

Octavian Fratu

ofratu@elcom.pub.ro

1 University of Montenegro, Cetinjska 2, 81000 Podgorica, Montenegro

2 Faculty of Electrical Engineering and Information Technologies, Ss. Cyril and Methodius University in Skopje, Skopje, Macedonia

3 Faculty of Electronics, Telecommunications and Information Technology, POLITEHNICA University of Bucharest, Splaiul Independentei, nr. 313, Sector 6, 060042 Bucharest, Romania 
significance of such vision and its impact on future societal, networking and communications landscape. In that manner, a smart world will be becoming our reality, with a number of attractive applications: smart cities and environments, smart grids, industrial automation, traffic management and logistics, remote monitoring, healthcare and assisted living, agriculture, public safety...

This special issue is mainly composed of the extended versions of selected papers presented at the 4th Center of TeleInFrastrukture-South-East Europe (CTIF SEE) Workshop: "Wireless applications and their societal impacts", 29 September 2015, Budva, Montenegro.

Further more, the issue also includes selected papers following the call for submissions of original research papers, both theoretical and practice-oriented, from academia, industrial professionals and students from various engineering fields, as well as innovative approaches and ideas regarding the ICT trends relevant for the creation of smart living and working environments.

We hope that this special issue will contribute to further research in the field of ICT with the focus on development of the smart world based on integration platforms providing new smart services and applications. The selected papers present the state-of-the art in the various aspects of research on ICT trends, offering an opportunity to the readers and researchers to pursue with their work on the issues still related with a number of challenges and open issues.

Finally, we would like to thank all the authors for their contributions, the reviewers for their valuable time and effort, as well as the members of the editorial team of the journal for their constructive support. Without this joint effort and commitment this issue could not be prepared.

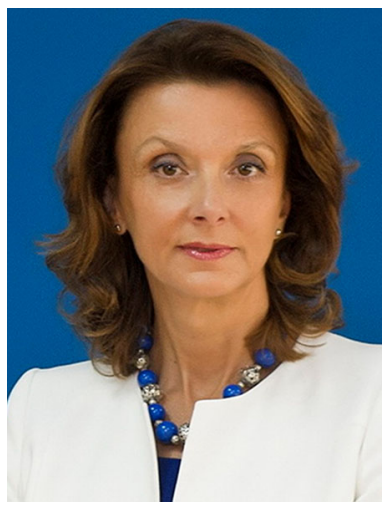

Milica Pejanović-Djurišić is a full professor in telecommunications at the University of Montenegro, Faculty of Electrical Engineering, Podgorica, Montenegro. She is also a director of the Research Center for Info-Communication Technologies at the University of Montenegro. In 1987, Mrs. Pejanovic-Djurisic has got Ph.D. degree in Telecommunications at the University of Belgrade. She has been teaching at the University of Montenegro basic telecommunications courses on graduate and postgraduate levels, as well as courses in mobile communications and computer communications and networks, being the author of four books and many strategic studies. Her main research interests are: wireless communications, $5 \mathrm{G}$ wireless networks, cooperative and energy efficient transmission techniques, optimization of telecommunication development policy. 


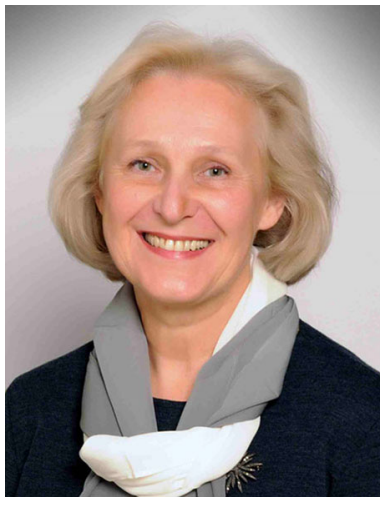

Liljana Gavrilovska currently holds the position of full professor at the Faculty of Electrical Engineering and Information Technologies, Ss Cyril and Methodius University in Skopje. She is also Head of the Center for Wireless and Mobile Communications (CWMC) and Head of the research WINGroup (Wireless Networking research Group) working in the area of the wireless and mobile communications. She has received her B.Sc, M.Sc and Ph.D. from Ss Cyril and Methodius University in Skopje, University of Belgrade and Ss Cyril and Methodius University in Skopje, respectively. Prof. Gavrilovska participated in numerous EU funded projects such as ASAP, PACWOMAN, MAGNET, MAGNET Beyond, ARAGORN, ProSense, FARAMIR, QUASAR, ACROPOLIS, CREW and eWALL, SCOPES funded ERTCON projects, NATO funded projects such as RIWCoS and ORCA and several domestic research and applicative projects. Her major research interest is concentrated on cognitive radio networks, future mobile systems, wireless and personal area networks, crosslayer optimizations, broadband wireless access technologies, ad hoc networking, traffic analysis and heterogeneous wireless networks. Prof. Gavrilovska is author/co-author of more than 250 research journal and conference publications and technical papers and several books. For her work she was awarded several recognition among them the highest national award "Goce Delchev". She is a senior member of IEEE.

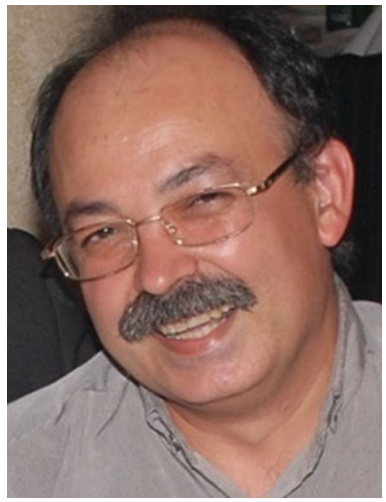

Octavian Fratu received the Ph.D. degree in Electronics and Telecommunications from University Politehnica of Bucharest, Romania in 1997. He pursued a postdoctoral stage as senior researcher in 3rd generation mobile communication systems, based on a research contract between CNET-France, ENS de Cachan-France and Universite Marne la Vallee-France. He is currently professor at the Faculty of Electronics, Telecommunications and Information Theory. His research interests include Digital Mobile Communications, Radio Data Transmissions, Mobile Communications and Wireless Sensor Networks. His publications include more than 200 papers published in national or international scientific journals or presented at international conferences. He participated as director or collaborator in many international research projects such as "Optimization and rational use of Wireless Communication Bands (ORCA)" (NATO Science for Peace research project, 2013-2016), ,Reconfigurable Interoperability of Wireless Communications Systems (RIWCoS)" (NATO Science for Peace research project, 2007-2010), ,REDICT-Regional Economic Development by ICT/New media clusters" (FP7 CSA project, 2008-2009), “ATHENA-Digital Switchover: Developing Infrastructures for Broadband Access", (FP6 STREP project, 2004-2006) and others. Currently he is UPB director of "eWALL for Active Long Living-eWALL” (FP7 IP project, 2013-2016). 